\title{
PLANIFICACION FAMILIAR EN EL POST-PARTO INMEDIATO
}

\section{Gonzalo Echeverry, M.D. Profamilia - Colombia}

Es un hecho reconocido universalmente que durante los primeros días del puerperio la motivación que tiene la mujer hacia la planificación familiar y hacia el control de su fecundidad alcanza el nivel máximo. No tanto por el recuerdo reciente de los sufrimientos físicos del embarazo y del parto, cuanto probablemente por encontrarse el instinto maternal elevado a su más alta potencia por el cuidado y protección del recién nacido, la mujer acepta y adopta con especial facilidad la idea de evitar nuevos embarazos por un tiempo para poder así entregarse totalmente al cumplimiento de sus deberes para con el hijo que acaba de nacer.

Por esta razón, los programas de planificación familiar que se ofrecen durante el estado puerperal tienden siempre a tener gran aceptación. A pesar de la tendenciosa crítica que se hace diciendo que ofrecer métodos anticonceptivos a una mujer que acaba de dar a luz es una coacción sicológica inaceptable, las campañas de planificación familiar deben dirigirse en lo posible hacia los programas post-parto para poder obtener provecho del alto grado de motivación que existe en la mujer.

Para efectos del presente trabajo se tiene en cuenta la clasificación de los programas post-parto del Consejo de Población que designa a las usuarias que aceptan y adoptan el método ofrecido antes de ser dadas de alta del hospital como "Aceptantes Inmediatas Directas" y a las que aceptan y adoptan el método entre
30 y 90 días después del parto como "Aceptantes Mediatas Directas". No se tienen en cuenta las "Aceptantes Indirectas" por considerar que no hacen en realidad parte de los programas hospitalarios post-parto.

Es muy frecuente escuchar en los medios de la especialidad obstétrica la opinión de que no existe justificación alguna para iniciar el uso de métodos anticonceptivos en el postparto inmediato. Las razones médicas en que se apoya esta afirmación son perfectamente valederas y difícilmente refutables si nos situamos dentro del terreno estricto de la especialidad, pero hay razones importantes para defender los programas de planificación familiar en el post-parto inmediato. En primer lugar, si es cierto como se dijo atrás que el uso de los anticonceptivos no es mejor en este momento que en el post-parto tardío, es también cierto y se puede sostener médicamente que el uso de los anticonceptivos en el post-parto inmediato no es nocivo ni perjudicial para la madre y no aumenta las estadísticas hospitalarias de morbilidad puerperal. Esta afirmación la comparten Banharsupawat y Rosenfield en su importante trabajo realizado en el hospital de mujeres en Bangkok, lo mismo que Tow, Goon y Lean en otra evaluación del programa post-parto del Hospital Kandang Kerbau de Singapur.

Por otra parte, si se examina el problema con criterio de campaña de planificación familiar más que con el criterio estrictamente gineco-obstétri- 
co, empiezan a aparecer razones importantísimas que justifican plenamente la insistencia en la planificación familiar iniciada en el post-parto inmediato.

Dado que los argumentos que se exponen más adelante están todos apoyados en la experiencia y en cifras estadísticas de los programas post-parto operados por Profamilia, se presenta a continuación un cuadro que resume las labores llevadas a ca- bo en el servicio de maternidad del Hospital General del Seguro Social en Bogotá, desde Mayo 1969, hasta Diciembre 1970. Este resumen muestra con claridad la amplia experiencia de Profamilia en este campo y cómo hay una base de 14.922 inserciones de dispositivo intrauterino post-parto que está respaldando las afirmaciones que se hacen más adelante.

En los 19 meses que contempla este trabajo manifestaron su aceptación

PROFAMILIA - ICSS

\section{Planificación Familiar Post-parto - Bogotá \\ Datos Globales}

Meses de trabajo

Casos obstétricos admitidos

Inserciones DIU en Post-parto inmediato

Inserciones DIU en Post-parto mediato

Cobertura
19

35.005

$10.922=31.2 \%$

$4.000=11.4 \%$

$14.922 \quad 42.6 \%$ para la inserción inmediata del DIU antes de ser dadas de alta del hospital 11.512 mujeres de las cuales se insertaron 10.922 )94.8\%) y fueron diferidas para inserción mediata 590 $(5.2 \%)$ por razones médicas que contraindicaban la inserción en el post-parto inmediato.

En cambio, en el mismo programa durante los 12 meses de 1970 manifestaron su aceptación para la inserción mediata del DIU (30 días postparto) 4.826 mujeres a quienes se les dió la correspondiente cita y de las cuales solo concurrieron para la inserción 2.195 (45.4\%), habiéndose perdido para el programa el $54.6 \%$ restante que no concurrió a las clínicas de planificación familiar. Resumiendo, de cada 100 aceptantes inmediatas se insertaron 95 y de cada 100 aceptantes mediatas, se insertaron 43.4 .
Es lógico pensar que una de las rafzones para esta amplia diferencia podría estar en que las aceptantes inmediatas fueran aquellas mujeres que tienen una más alta y verdadera motivación y que muchas de las aceptantes mediatas hubieran sido mujeres no suficientemente motivadas $y$ decididas, que aceptaron únicamente por no aparecer como negativas y librarse momentáneamente del problema.

Para comprobar esta hipótesis se suspendió durante 25 días la inserción inmediata del DIU y se dio cita a todas las aceptantes para 30 días después del parto. De ser cierta la hipótesis, el porcentaje de mujeres que cumpliera esta cita debería sobrepasar notablemente el $45.4 \%$. Se dieron 944 citas y entre los 30 y 90 días solamente concurrieron 415 mujeres $(43.4 \%)$. En vez de subir, el porcen- 
taje bajó ligeramente, lo cual demuestra que no es el grado de motivación sino el tiempo transcurrido lo que hace que se pierdan más de la mitad de las mujeres con cita mediata.

Pero viene enseguida la conocida objeción: El DIU insertado en el post- parto inmediato se expulsa con altísima frecuencia. Es la verdad. De una muestra de 2.000 casos de Asa de Lippes insertada en post-parto inmediato en el programa de Profamilia, $896(44.8 \%)$ expulsaron el dispositivo en los primeros 30 días sólo se perdieron realmente 48 casos $(2.4 \%)$.

\section{PROFAMILIA - ICSS \\ Planificación Familiar Post-parto - Bogotá \\ Estudio de una muestra de 2.000 casos en los primeros 30 días \\ después de la inserción de DIU en el post-parto inmediato}

\begin{tabular}{lc}
\hline Expulsión & $896=44.8 \%$ \\
Reinserción & $848=94.8 \%$ \\
Casos cerrados por expulsión & 48 \\
\hline
\end{tabular}

Hay razones claras para que casi la totalidad de las mujeres que expulsaron el DIU hubieran concurrido a la reinserción: La alta motivación con que aceptaron el procedimiento y la muy cuidadosa e insistente instrucción que recibieron en la cual se les advirtió hasta la saciedad la probabilidad de expulsión, se minimizó al máximo la importancia de esta y se insistió también al máximo la necesidad de concurrir a la clínica para la reinserción. Queda claramente demostrado como el elevado índice de expulsiones tempranas del dispositivo no es de ninguna manera un inconveniente para insistir en la inserción en el post-parto inmediato.

En todo método anticonceptivo la verdadera eficacia está en la continuidad o tasa de retención a largo plazo. De los 2.000 casos estudiados de DIU en el post-parto inmediato, estaban activos (in situ sin embarazo) después de un año de la inserción el $58.9 \%$ de las insertadas, lo cual es ciertamente un poco más bajo que el índice de retención para el DIU insertado fuera del post-parto (66.5\%).
Pero la ventaja está más compensada por el número de inserciones inmediatas por cada 100 aceptantes que es casi exactamente el doble de las inserciones mediatas por cada 100 aceptantes.

En conclusión, existen claras razones para continuar en nuestro medio con la inserción del dispositivo intrauterino en el post-parto inmediato. La desafortunada experiencia de otros programas como el del hospital Kandang Kerbau de Singapur o la Maternidad Concepción Palacios de Caracas, que eliminaron de sus programas post-parto la inserción inmediata del dispositivo, ha podido ser debida a que no se insistió suficientemente en la motivación e instrucción muy cuidadosa de las aceptantes. Una vez más se demuestra la importancia definitiva que un buen programa educativo tiene en toda campaña de planificación familiar.

Por vía de experimento se ofrecieron durante cuatro meses anticonceptivos orales a las mujeres en postparto inmediato, al mismo tiempo 
que se les ofrecía el dispositivo intrauterino. El método tuvo buena aceptación de momento por parte de las puérperas, pero al estudiar la continuidad apareció este sistema como un fracaso absoluto.

Se siguieron 896 aceptantes que iniciaron el tratamiento con píldoras en el tercer día post-parto. De estas, únicamente 299 (33\%) concurrieron a las clínicas para reclamar la segunda dosis, o sea que en el primer mes ya había una tasa de abandono de $67 \%$. Con más de dos controles registrados sólo hubo 48 casos ( $5 \%$ ) lo que indica que a los tres meses la tasa de abandono alcanzaba el $95 \%$. Por esta razón Profamilia canceló el programa de píldoras en el post-parto inmediato.

El éxito de los programas post-parto no depende exclusivamente de los métodos empleados. Hay que desarrollar una técnica de trabajo sufi- cientemente perfecta que permita instruir y motivar a las mujeres desde la primera consulta pre-natal para que ellas puedan adquirir la conciencia de la planificación familiar y utilicen el tiempo de embarazo para discutir con sus maridos la conveniencia de planificar la familia después del nacimiento del hijo que se está esperando.

El programa educativo debe continuar inmediatamente después del parto para aprovechar la motivación natural existente y guiar a las nuevas madres hacia la adopción de un sistema. Un buen programa educativo da necesariamente como resultado un mayor número de aceptantes y una mayor continuidad en los métodos. De acuerdo con la experiencia adquirida en los programas post-parto de Profamilia, se requieren para educación y motivación cuatro veces más horas de trabajo que para el servicio médico. 